\title{
Managing English Language Centres in the UK: Challenges and Implications
}

\author{
Abdulaziz Fahad Alfehaid
}

\begin{abstract}
This paper contends that English language centres (ELCs) offering English courses to non-native English speaking students at the higher education level in the UK face some distinct though interrelated challenges. The argument is that these challenges if not dealt with, would have a negative impact on the quality of English language teaching and learning. Three major issues are discussed including financial funding, government control, and diversity and multiculturalism. The paper provides a deeper insight into these major challenges and suggests some possible implications for managing these challenges.
\end{abstract}

Index Terms-English language centres, English speaking students, management.

\section{INTRODUCTION}

The purpose of this paper is to understand the nature of some challenges involved in managing a centre for teaching English language to non-English students in the UK's higher education institutions and, on the basis of this understanding, help stakeholders overcome these challenges. The number of international students who are admitted to UK's universities and whose first language is not English is rapidly growing. According to the English UK - the national association of English language teaching centres, more than 600.000 overseas students every year come to the UK to study English at ELCs [1]. It is reported that every year the English UK receives around 35 complaints against its ELC members [2]. In a recent study, 54 percent of international students studying English in different British universities expressed their dissatisfaction with the services provided to them particularly the quality of teaching [3].

Of course managing a centre that runs English language courses for overseas students or, whose native language is not English in the UK at the higher education level, inarguably would come at some cost especially when the demand for it is high and competition is fierce.

This paper will be in two folds. Firstly, I will discuss some challenges that might be involved in managing ELCs in the UK, and secondly explore some of the ways in which such challenges could be overcome, whilst at the same time highlighting their implications. This will be followed by a conclusion which provides a summary of all the major discussions going to take place in this paper.

Manuscript received August 15, 2014; revised October 20, 2014

Abdulaziz Fahad Alfehaid is with the University of Dammam, Saudi Arabia (e-mail: aalfehaid@ud.edu.sa).

\section{Challenges in Managing English Language CENTRES}

This section focuses on some of the challenges that might emerge in operating ELCs in the UK. It will explore the issues of financial funding for the centres, government control, and also the issue of diversity and multiculturalism.

\section{A. Financial Funding}

Due to marketing strategies employed by colleges, universities, and other learning institutions in higher education to attract foreign students from China, the Middle East and Africa, there has been a high proliferation for the need to study English as a second language, in order to gain access to western institutions (particularly those in the UK and US) to study different subject areas [4]. However, despite the proliferation of interests, and the huge sums of money usually charged by institutions, funding and financial management sometimes remains difficult. For instance, political parties of all persuasions normally use education in their campaigns to gain votes - want the quality of education provided to improve, but they actually want to do it at lower cost [5]. This highlights the fact that governments' support for better and quality education more often than not stays at the margins, because of more important engagements. This in turn might reduce the amount of money that governments give to institutions and because of the limited nature of the money that such institutions receive, they in turn might become more careful in their spending, prioritising their expenditure. This may force institutions in higher education to invest their limited finance on the most important departments (like science, medicine, research and development etc.). It has been reported, in some cases, English language centres are often seen by some UK universities as money making mechanisms, and because of this, the money they make is often taken from them and invested in other areas other than the English language centres [6].

This might leave the English language centres in these universities with very limited financial power or resources, which can create difficulties in managing and running them. This often creates far reaching human and material resource implications. Firstly, because of the lack of money, it can be said that one encounters an inadequate number of staff running the whole centres, which leads to more complex problems in terms of service delivery. It is argued that because of insufficient staffing, most of the working staff end up being overloaded with work, which in the long run leads to staff taking sick leaves etc., leading to absenteeism and employee turnover [7]. This may result to management 
difficulties in terms of running the centre, because recruitment, selection, and motivation of people may become impossible. Motivation plays a major role in increasing levels of job satisfaction [8]. Because virtually there is no money to spend on maintaining staff, it becomes extremely difficult to otherwise fulfill the 'psychological contract' with staff and also to give them a reason to stay [7]. This psychological contract is necessary for achieving expected outcomes for both employees and employers [9]. "Reference [9] says: this psychological contract is essentially a set of expectations. We have a set of results that we expect from the organisation, results that will satisfy certain of our needs and in return for which we will expand some of our energies and talents. Similarly the organisation has its expectations and its lists of payments or outcomes that it will give to us (45)".

The absence of this contract can trigger discontent, resistance, sabotage and anti-management sentiments, which breeds an atmosphere of distrust and hatred for managers and their employees.

Secondly, there is the issue of inadequate materials or supporting resources to facilitate management to deliver quality and efficient services. As in [10], quality can be determined by the degree to which expected objectives achieved, fitness for purpose, added value and client satisfaction. Most people who take up English as their second language come to English language centres with complex needs and requirements. To cater for diverse and complex needs, English language centres need more than the basic or elementary requirements and resources. The process of planning the allocation of limited financial resources often consumes a lot of management's time, which in itself leaves very little time for other management tasks. "Reference [5] argues that a clear link exists between resources and the quality of education that an institution is able to provide." It is very obvious that more money although does not necessarily mean more resources, however it could be translated into more resources to provide better and quality services to the service users and also improve motivation of staff to enable them to do a better job.

\section{B. Government Control}

As in [5], possibly the most significant is the state's involvement in education, not only in the funding, but also in the control of the system, and the outcomes of the educational processes that they fund. Although this argument more or less focuses on governments determining how the systems should be operated, I want to add that governments nowadays also determine who should access academic institutions. Since the 9/11 incident and other subsequent attacks in different parts of the world, particularly the 7 July 2005 London bombings, governments overnight have become very vigilant on overseas people and foreigners. This has resulted and is reflected in their screening procedures, anti-terrorism laws and the fortification of their gates. Such measures of control may have probably reduced the number of intakes that academic institutions used to enjoy, thus constraining an avenue of making money. The UK government urged its universities in the UK to take proactive measures in checking and monitoring their foreign students particularly those from the Middle East [11]. This form of control or government involvement in academic institutions' affairs also might raise difficulties for managing English language centres because this often triggers a situation whereby discrimination on the basis of nationality, religion or race may take place, especially when there are laws and acts established to deal with those who infringe them. This brings us to the issue of diversity and multiculturalism.

\section{Managing Diversity and Multiculturalism}

As academic institutions are becoming increasingly enriched by the presence of people from different socio-cultural and ethnic backgrounds, managing diversity and multiculturalism become very imperative and a very significant management issue. Critical to the management of diversity and multiculturalism, is changing the organisation to accommodate the diversity of the administrative and academic staff as well as the students [12]. This, "Reference [12] says: will entail becoming a learning organisation in which the appropriate culture is one which is capable of constant adaptation as the needs of the stakeholders change." Thus, this would mean improved outreach, user-education, support services and physical facilities to accommodate all users, especially students of diverse ethnic, cultural and religious backgrounds, older students, users with disabilities, and students at risk of attrition, through partnerships and informed programming, in order to improve their academic success and information literacy.

Diversity in its broadest sense is often taken to imply human groupings based on race, ethnicity, gender, culture, class, age, religion, sexual orientation, learning styles, nationality, and disability [13]. In addition, it goes beyond the mere existence or the tolerance of people and symbols from different cultures and backgrounds [14]. It also means inclusion and equity. However, understanding and valuing diversity is only the first step for managing or running an English language centre. Managers of English language centres also have the management task of translating such understandings into activities undertaken by all their members in order to create an inclusive and welcoming climate for students, faculty, and staff. This process is multifaceted, involving interactions both inside and outside classrooms. A welcoming and inclusive climate is grounded in respect for others, nurtured by dialogue between those of differing perspectives, and is evidenced by a pattern of interaction among members.

It is the case that academic institutions are becoming uniquely challenged by changing national, regional and international demographics [15]. As student populations become more diverse, academic institutions are expected to create and maintain a healthy learning environment among students, many of whom probably have had few opportunities in the past to develop deep familiarity with other cultures [15]. In this sphere, managing or running a centre for teaching English language might involve developing a shared and inclusive understanding of diversity, creating a welcoming climate, recruiting, retaining, and successfully graduating a diverse student body; advancing, and retaining a diverse staff team, developing a curriculum that supports the diversity goals of the centre, diversifying its leadership and management, and organizing for change to 
support diversity goals. To this effect, it then becomes very imperative for managers of English language centres to be culturally competent and alert in terms of the different socio-cultural needs of the students and staff they enroll or employ.

\section{ReCOMMENDATIONS FOR OVERCOMING CHALLENGES IN MANAGING ELCS}

Based on the analysis of the challenges above, funding can be one of the most important factors in managing English language centres. Some academic institutions that run English language centres focus more on marketing their courses rather than the quality of teaching. Academic departments are judged and funded, by the Research Assessment Exercise, on the quality of their research without taking the standard of teaching into consideration [6]. The lack of quality of teaching might be based on the premise that more students would mean more money, and fewer students less money, thus leading to a race to capture the most students by spending huge sums of money on marketing and advertisements. This might create a situation where students are perceived as commodified objects because of the money they bring along rather than as seekers of knowledge who want to learn to improve and develop their potentials, as in reference [6], a "leading historian says that the scramble for foreign students' fees is destroying our academic reputation". In addition, "Reference [6] says: one experienced lecturer at the University of Plymouth said that a new English language centre had been set up specifically to attract overseas students, especially from the Far East, to the campus business centre... I saw a lot of dedicated, hard-working Chinese students who were just being used to make money. But already some Chinese parents and companies are beginning to question the quality of the course."

Rather than spending an unimaginable amount of money on marketing and advertisement and ending up providing poor services to students, universities that manage English language centres should try to draw their budgets in such a way that less money is spent on marketing and more money on service provision and the generation of more resources. By doing this, they could be able to provide quality services, facilities and resources, even if it means fewer students, because quality will sell itself. Once this image is achieved, they might then be in a position to increase fees in order to gain surplus over their costs of operation. Recent research suggests that there is a relationship between higher tuition fees and the provision of better teaching [16]. This is because the higher fees create surplus, which in turn is reinvested in acquiring better facilities, better and more resources, and also the general motivation of staff members. In addition, as in Reference [16], "higher fees translate into more teaching provision. When universities are funded mainly via students, rather than from central government, people will pay for better teaching and they will get what they pay for" (1). Broadly speaking, reputation of good quality of teaching can attract many people. However, the implication with this recommendation is that it is more of a long term strategy than a short term one. This is because it may take a longer term to establish an image, especially if it is to be an international reputation of quality delivery service.

The second recommendation ties into government control. Addressing this challenge is much more complex and complicated than it may seem to appear because most academic institutions or centres cannot be immune from government interference. A legal provision mandates governments through some of their instruments to interfere. In fact, a total freedom from government interference might not be achieved. However, the government interference can be minimised to some extent. This can come from the minimisation of financial dependency on governments for funds, because it is obvious that governments will fund academic institutions or learning centres only to achieve their socio-economic and political objectives. Thus, linking back to the first point, being able to build a good reputation for excellent service delivery and charging higher fees to students could dramatically reduce financial dependency from governments.

Finally, we have the issue of diversity and multiculturalism. As stated above, it is not only sufficient to understand these two concepts, rather any such understanding would need to be translated into visible and tangible activities and must be reflected in every action of the language teaching centre or English Language department. Managing diversity should start from the very top of the institutions and should be demonstrated in the day-to-day practices and thoughts of the institutions. This to some extent could involve a change process, which may affect structures, culture and strategies. However, undertaking such a change could be massive, time-consuming and probably expensive depending on the size of the centre of the institution. It may also be met with resistance where the interests of some people become under threat. But at the same time one always should consider the long term gains.

\section{CONCLUSION}

In this paper, I have argued that there are three key challenges that could be anticipated in managing or running an English Language centre, school or institution in the UK at the higher education level. I discussed the problem of financial funding faces or could potentially face centres in terms of human and material resources. I highlighted this challenge as the core or gateway for arousal of other challenges or problems like that of government control and interference. In addition, I discussed issues of diversity and multiculturalism. Indeed, diversity also stands out as a significant challenge, especially when the majority of intakes in English Language centres are usually foreign students coming from different socio-cultural backgrounds.

Other than analysing the challenges, I also provided some recommendations for overcoming such challenges together with their implications. I dwelled on the issue of creating financial independence through quality provision which in turn could be translated into reputation and eventually charging higher fees. I highlighted that government interference cannot be ultimately avoided because of legal provisions, but it could be minimised through the minimisation of financial dependency on government funding. 


\section{REFERENCES}

[1] English UK. (May 2014). English UK celebrates its 10th birthday. [Online]. Available: http://www.englishuk.com/en/agents/english-in-the-uk/english-uk-ne wsletter/spring-2014? article $=0$

[2] English UK. (August 2013). Student complaints' procedure. [Online]. Available:

http://www.englishuk.com/uploads/assets/student_complaints_sheet_ updated_English.pdf

[3] A. Alfehaid, "Quality of teaching and service: are students getting what they expect from English language centers (ELCs)?" presented at the International Symposium of Foreign language education and its applications in Prep Classes, Marmara University, Istanbul, Turkey, October 10-13, 2012.

[4] S. Marginson and G. Rhoades, "Higher education beyond nationalstates, markets, and systems of higher education: a glonacal agency heuristic," International Journal of Higher Education, vol. 43, no. 3, pp. 281-309, August 2002.

[5] J. Ivy, "Management in English language teaching," Unpublished Handout, April 2006.

[6] M. Bright. (March 2011). Slow corruption that threatens our universities. [Online]. Available: http://www.education.guardian.co. uk/universitiesincrisis/story.html

[7] M. Suazo, H. Turnley, and R. M. Dalton, "The role of perceived violation in the determining employees' reactions to psychological contract breach," Journal of Leadership and Organisational Studies, vol. 34, no. 1, pp. 57-62, 2005.

[8] J. Carey and M. Dabor, "Management education: an approach to improved English language teaching," ELT Journal, vol. 49, no.1, pp. 37-43, 1995.

[9] C. Handy, Understanding Organisation, Harmondsworth: Penguin, 1993.

[10] H. Thomas, "The arguments for and the meaning of quality," ELT Journal, vol. 57, no. 3, pp. 234-241, 2003.

[11] A. Fazackerley. (May 2013). Terrorism Vetting Chaos: MPs to Attack Universities for Ignoring Government Safeguards. [Online]. Available: http://www.education.guardian.co. uk/higher/news/story.html
[12] B. Norris, "Managing cultural diversity within higher education: a South African perspective," Intercultural Communication, vol. 3, April 2000.

[13] A. Gordon, "The work of corporate culture: diversity management," Journal of Social Text, vol. 44, no. 2, pp. 3-30, 1995.

[14] L. Kessler, Managing Diversity in an Equal Opportunity Workplace: A Primer for Today's Manager, Washington DC: National Foundation for the Study of Employment Policy, 1990.

[15] UCR, A Framework for Diversity at UC, California: California University, 2004.

[16] P. Andras and B. Charlton. "The student purse can save us from the mediocre," The Times Higher Education Supplement, January 2003.

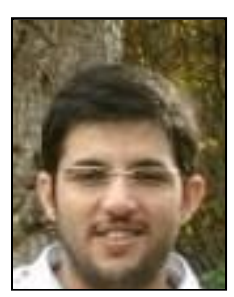

Abdulaziz Fahad Alfehaid holds an MA and a Ph.D in applied linguistics and TESOL from the School of Education at the University of Leicester (UK). He is an assistant professor in the English Department at the University of Dammam (Saudi Arabia) and he has been a faculty member since 2003 . His $\mathrm{PhD}$ research is focused mainly on evaluating English language programs particularly EAP and ESP programs. Dr Alfehaid has taught applied linguistics and EFL, and consulted on assessment, program evaluation projects and pedagogy in ESL and adult education settings. He currently holds the position of dean of preparatory year as well as vice-dean of admission and registration in the University of Dammam and is an active member of the committee on the quality of university teaching and learning as well as a member of the institutional self-study team. He also serves on and chairs a number of national and international steering groups and committees and international conference programs. He received formal training in ESL/EFL program review and evaluation and has gained practical experience in most aspects of the field while working as a CEA external reviewer. 